\title{
Present insight on achalasia - from diagnosis to treatment
}

\author{
Jacek Dziedzic', Norbert Nowak', Witold Zgodziński' ${ }^{1}$ Paweł Bury'1, Grzegorz Wallner', \\ Krzysztof Zinkiewicz' \\ 1 2nd Department of General \& Gastrointestinal Surgery and Surgical Oncology of the Alimentary Tract, Medical
University in Lublin, Poland
}

Dziedzic J, Nowak N, Zgodziński W, Bury P, Wallner G, Zinkiewicz K. Present insight on achalasia: from diagnosis to treatment. J Pre-Clin Clin Res. 2019; 13(2): 92-98. doi: 10.26444/jpccr/105827

\begin{abstract}
Introduction. Achalasia is a most frequent primary motility disorder of the oesophagus with the prevalence of $10 / 100,000$ individuals, with no gender predominance. Due to its rare occurrence, at the early stages may be erroneously diagnosed, leading to progression of disease and delayed treatment.

Objectives. The main aim of the review is to depict current data about achalasia, including pathogenesis, diagnosis, and possible treatment modalities, particularly the latest, minimally invasive technique: per-oral endoscopic myotomy (POEM). State of knowledge. The ethology of achalasia remains unknown, although autoimmune, viral or neurodegenerative causes may be considered triggers of the disease. In some cases, achalasia may be secondary to other conditions (e.g. malignancy, Chagas disease). Typical symptoms of achalasia are dysphagia (for both liquids and solids), regurgitations, heartburn and weight loss. The diagnosis is based on endoscopy, oesophageal high-resolution manometry (HRM) and X-ray with barium swallow. Therapies used in the treatment of achalasia focus on improving food passage by reducing LES pressure. These procedures include pharmacologic treatment, pneumatic balloon dilation, Heller myotomy and endoscopic myotomy. POEM was first introduced in humans by Inoue in 2008. Recent studies have revealed excellent short-term outcome of POEM with no serious complications.

Conclusion. Achalasia is an incurable disease; however, available therapies can effectively reduce patients' symptoms. Further evaluation may lead to the establishment of tailored-to- patient treatment, and it is believed that POEM will become a gold standard for treatment of achalasia.
\end{abstract}

\section{Key words}

oesophageal achalasia, oesophagoscopy, manometry, dilatation, myotomy

\section{INTRODUCTION}

Idiopathic achalasia is a rare motility disorder which can be characterized by two main features: lack of peristalsis and defective relaxation of the lower oesophageal sphincter (LES). It is often accompanied by elevated values of LES pressure. Historically, Sir Willis was the first to describe the condition of loss of normal inhibition in the distal oesophagus [1]. Almost two centuries later, Mikulicz attached the designation "cardiospasmus" to idiopathic dilatation of the oesophagus, believing that the spasm of the cardia was responsible for the disease [2,3]. In 1927, Hurst and Rake proved relationship between the absence of Auerbach 's plexus of nerve cells in the oesophageal wall and insufficient muscular contractions of the oesophagus, often failing to reach the cardia [4]. They introduced the term "achalasia", derived from the Greek khalasis - not relaxing or loosening.

Current epidemiological studies report an approximate incidence of 1/100,000 individuals annually and prevalence of 10/100,000 [5-7]. A study by Samo et al. suggests that this data is underestimated, and the incidence and prevalence are at least 2-3-fold greater than previous estimates [8]. Achalasia occurs equally in men and women with possible racial predominance, as the higher percentage of women presented with achalasia has been reported in blacks, compared to

Address for correspondence: Jacek Dziedzic, 2nd Department of General \& Gastrointestinal Surgery and Surgical Oncology of the Alimentary Tract, Staszica 16 20-081, Lublin, Poland

E-mail: jckdziedzic@gmail.com

Received: 25 February 2019; Acepted: 19 March 2019; first published: 03 June 2019 whites or other races [9]. The risk of disease increases with age, with two peaks of incidence: between 20-40 years of age and from the age of 60 onward. Diagnosis before the second decade is rare [10].

Pathophysiology. Coordinated oesophageal peristalsis depends on the balance between excitatory innervation of the vagus nerve and inhibitory supply by the cervical and thoracic sympathetic trunk [11]. Acetylocholine output by the vagus nerve initiates oesophageal peristalsis, whereas nitric oxide (NO) and vasoactive intestinal polypeptide (VIP) released by inhibitory neurons relax the muscle wall and LES [12]. In the initial stage of the disease, degeneration of ganglion cells in the myenteric plexus results in the dominance of excitatory neurotransmitters which leads to failure of LES relaxation and loss of oesophageal peristalsis. In primary achalasia, the triggering event of the ganglion cell degeneration is unknown $[10,13,14]$. Immunohistochemical analysis of samples taken during oesophagomyotomy demonstrated a significant decrease of both enteric neurons and interstitial cells of Cajal. Moreover, CD3 staining disclosed myenteric plexitis in $42 \%$ of patients, reaffirming a possible inflammatory background [14]. Autopsy samples, and resection specimens of patients undergoing oesophagectomy for end-stage disease, showed hypertrophy of the oesophageal musculature, fibrosis and depletion of myenteric ganglia [15]. Several cases of familial achalasia diagnosed between siblings and in monozygotic twins suggest a genetic predisposition. These cases have been mostly seen in the paediatric population $[16,17]$. Multiple genetic mutations, such as nitric oxide synthase 1 gene 


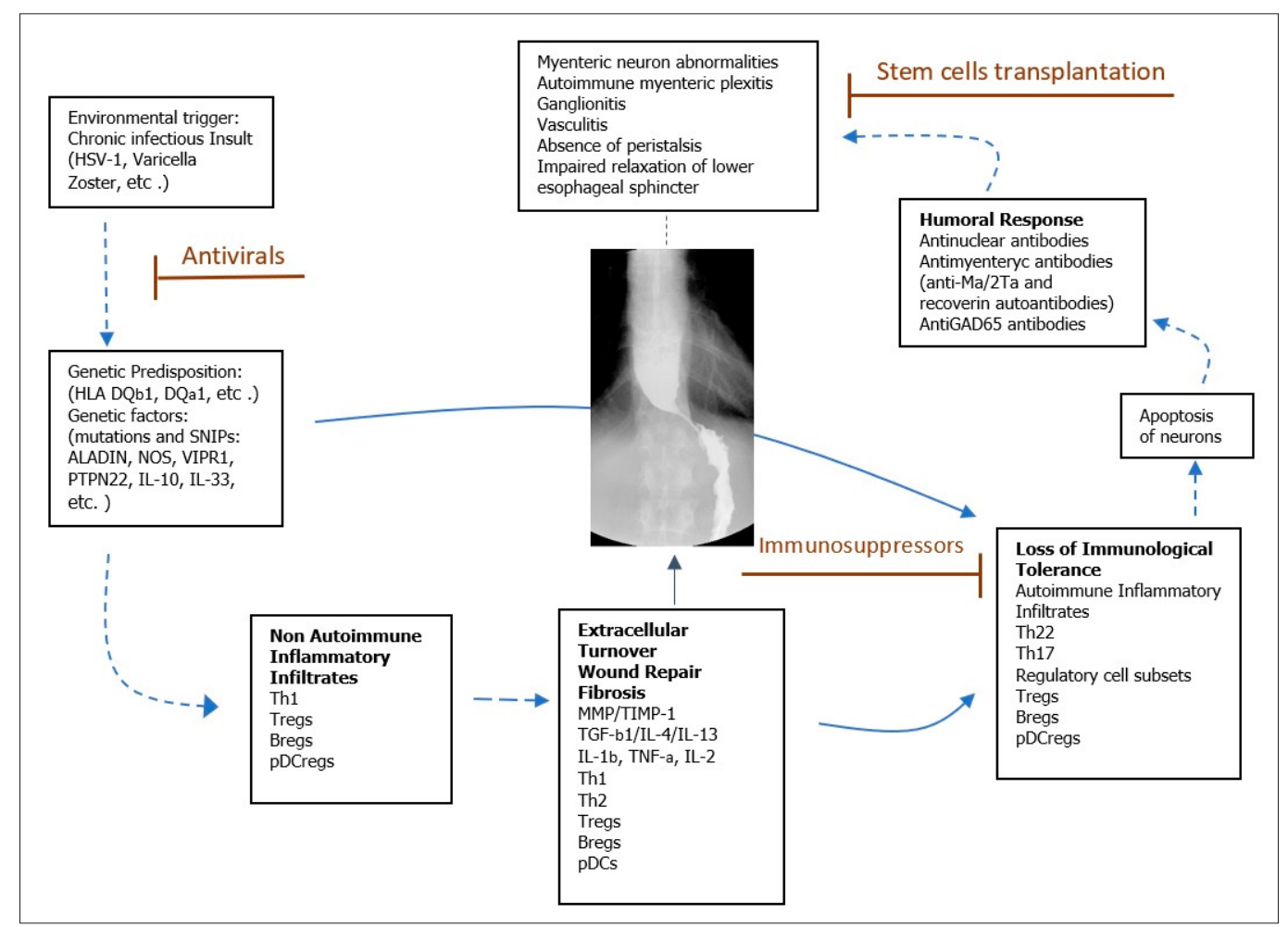

Figure 1. Proposed model of achalasia pathophysiology (modified from Furuzawa-Carballeda et al [29]).

(NOS1), VIP receptor 1, IL23R, IL10 promoter, IL 33, and protein tyrosine phosphatase non-receptor 22 (PTPN22), proved to be related to the development of achalasia [1824]. Mutations in the AAAS gene on chromosome 12q13, encoding the nuclear pore protein ALADIN, lead to triple A syndrome (TAS), also known as Allgrove syndrome, which is an inherited condition characterized by three specific features: achalasia, Addison disease, and alacrima [25]. Some authors have hypothesised an association between viral infection and the development of achalasia, because elevated values of antibody titer against measles have been observed in achalasia patients, compared with controls. Additionally, DNA particles of Varicella zoster virus (VZV) were present in tissue specimens from achalasia patients [26]. Cytomegalovirus (CMV), herpes simplex virus type 1 (HSV-1), Epstein-Barr virus and human herpes virus-6 were also evaluated for relationship; however, no study was able to present strict evidence [27]. Achalasia may likewise be a consequence of Chagas disease, in which parasite infection of Trypanosoma cruzi leads to myenteric plexus destruction [13]. Another possible ethology is an auto-immune response with a T-cell lymphocyte infiltration targeting the myenteric plexus. Vaezi et al. reported that the overall prevalence of neural autoantibodies in patients with primary achalasia was significantly higher than in healthy control subjects ( $25.7 \%$ vs $4.4 \%$; $<0.0001$ ) [28]. The autoantibodies against myenteric neurons were especially found in carriers of DQA $1^{\star} 0103$ and DQB1 ${ }^{\star} 0603$ alleles [29]. All these evidences lead to the conclusion of a multi-factorial background, characterized by abnormal immune response to an infectious agent in genetic susceptible individuals, resulting in inflammation and degeneration of neurons supplying muscular wall of oesophagus (Fig. 1).
Pseudoachalasia. Opposite to idiopathic achalasia, pseudoachalasia occurs due to a secondary condition in which achalasialike symptoms mimic another abnormality. This accounts for only $2.4-5.4 \%$ of patients with clinical and manometric signs of achalasia and tends to occur in the elderly [30].

In most cases, pseudoachalasia results from malignancy (68.8\%), mainly gastric fundus adenocarcinoma and squamous cell carcinoma of the distal oesophagus. Less frequently, it is due to benign lesions, vascular obstruction or as a consequence of previous surgical procedures, such as Nissen fundoplication or bariatric surgery [31]. Oesophageal motility disturbances may be an effect of paraneoplastic phenomenon (e.g. with small cell lung cancer) [15]. The differentiation between pseudoachalasia and achalasia is challenging, therefore, a thorough diagnostic process including detailed anamnesis, computerized tomography, endoscopic ultrasonography, oesophageal manometry and oesophagogastroscopy with biopsy, is crucial. The successful treatment of the underlying disorder makes the complete reversal of symptoms achievable [32].

Clinical appearance. Impaired LES relaxation with aperistalsis lead to a wide range of symptoms which adversely affect the quality of life and daily activity. Most commonly, achalasia patients present with progressive dysphagia for liquid and solids (91-100\%), as well as regurgitation of saliva or food remains (76-91\%), weigh loss (35-91\%), chest pain (25$64 \%)$ and heartburn (27-42\%) [33]. Sinan et al. analysed the prevalence of respiratory symptoms in patients with achalasia, and concluded that almost every second patient complained of at least one symptom daily, including cough (37\%), aspiration (31\%), hoarseness (21\%) and wheezing (15\%) [32]. Spirometry assessment of untreated patients showed abnormalities in $45 \%$ of patients [34]. Respiratory symptoms result from recurrent 
aspiration of food debris and tracheal compression from the dilated oesophagus. Heartburn most commonly precedes the onset of dysphagia, consequently leading to the misdiagnosis of achalasia as a gastro-oesophageal reflux disease (GERD). Furthermore, younger patients are more likely to report heartburn and chest pain. The low incidence of achalasia in the general population frequently result in numerous consultations with a physician and delayed diagnosis. The prospective study proved a significant association between the duration of symptoms prior to considering the diagnosis of achalasia and the number of unsuccessful physician consultations [35]. For a more accurate evaluation of symptoms' severity, the Eckardt score was introduced into clinical practice [36]. It grades the four most common symptoms based of their frequency of occurrences and the maximum score is 12 (Tab.1). The Eckardt score allows determination of the intensity of symptoms at baseline, as well as to compare them with postoperative result and establishing the efficacy of treatment. Reduction in the Eckardt symptom score to three, or less, is regarded as a treatment success [37].

Table 1. Eckardt symptom score

\begin{tabular}{lcccc}
\hline & Dysphagia & Regurgitation & Chest pain & Weight loss $(\mathrm{kg})$ \\
\hline 0 & None & None & None & None \\
\hline 1 & Occasional & Occasional & Occasional & $<5$ \\
\hline 2 & Daily & Daily & Daily & $5-10$ \\
\hline 3 & Each meal & Each meal & Each meal & $>10$ \\
\hline
\end{tabular}

Diagnosis. Among many different diagnostic modalities, endoscopy, barium swallow and high resolution manometry provide the most relevant data enabling confirmation of the suspicion of achalasia, based on clinical symptoms. Radiology and endoscopy are reasonable at the beginning of diagnostics in order to exclude other pathologies. Rapidly progressing dysphagia, significant weight loss, and old age raise the suspicion of pseudoachalasia and should prompt the performance of more sophisticated tests, such as endoscopic ultrasound or CT scan. During differentiation between pseudoachalasia and achalasia, widely-available transabdominal ultrasonography allows visualization of the gastric cardia with its surrounding structures [38]. Due to abnormal inhibitory innervation in achalasia, the cholecystokinin-octapeptide (CCK-OP) test can be performed during work-up. In normal patients, intravenous bolus of CCK-OP results in LES relaxation because of inhibitory neurons excitation, whereas in achalasia, loss of the inhibitory neurons induces LES contraction [39].

Oesophagogastroscopy. As mentioned above, the main role of endoscopic evaluation is to rule out oesophageal cancer, structural lesions (strictures, webs, or rings), eosinophilic oesophagitis, GERD, or even pancreatic cancer infiltration [40]. Although $44 \%$ of patients may present with an intact appearance of the oesophagus [41], it is more likely that typical features of achalasia will be found, e.g. oesophageal dilatation, atony and food or fluid retention. Resistance during passage of the endoscope through the oesophagogastric junction (EGJ) is commonly observed; however, increased resistance may suggest a coexisting neoplastic infiltration [38]. Despite oesophageal candidiasis being a rather rare clinical manifestation of achalasia, it ought to be considered as a symptom of oesophageal dysmotility among individuals with no immune disorders. Recently, a novel endoscopic indicator of oesophageal achalasia has been proposed by Minami et al., dedicated particularly to those without typical endoscopic findings. A "pinstripe pattern" (PSP) is formed by longitudinal superficial wrinkles after spraying indigocarmine on the mucosa surface. The prevalence of PSP was observed in $60.7 \%$ of achalasia patients, while none of the control showed positivity for PSP [42]. Endoscopic achalasia signs need confirmation in further testing.

Barium swallow. The initial diagnostic also includes barium swallow (oesophagogram). It is a non-invasive imaging technique which allows the recognition of achalasia in $60 \%$ of patients, although the early stage of the disease may yield a normal result or imitate other conditions [43]. It classically shows lack of peristalsis, dilated oesophagus and narrowing of the EGJ- the bird-beak appearance, considered as a radiological hallmark syndrome of achalasia (Fig. 2). In more advanced cases, abnormal enlargement of the oesophageal body-megaoesophagus or a sigmoid-like shape may occur. Barium swallow can be helpful in defining oesophageal measurements (diameter and axis), as well as presenting mechanical obstructions and epiphrenic diverticula. To assess oesophageal emptying or effectiveness of treatment, timed barium swallow (TBS) is performed. It includes the intaking of $100-250 \mathrm{~mL}$ of solution in a vertical position, and taking radiographs at the beginning and after five minutes. The height from the EGJ to the top of barium column is measured at both points of time.

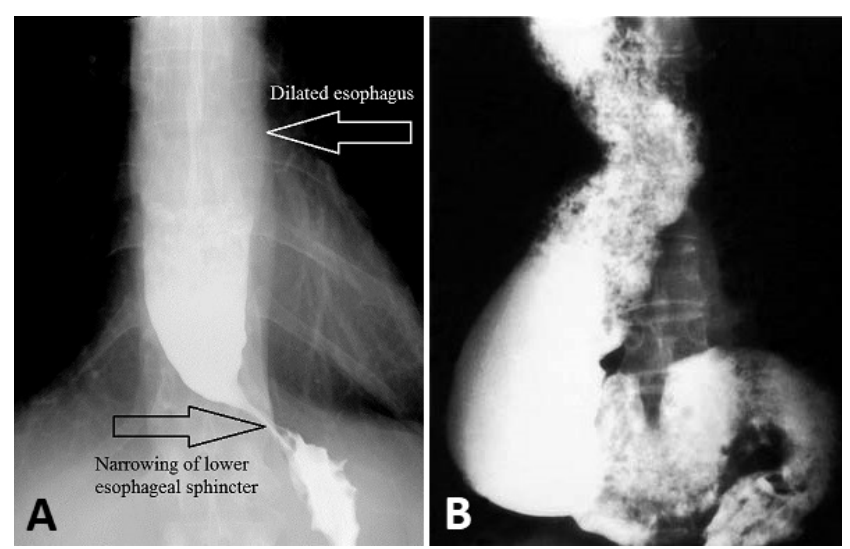

Figure 2. Oesophagograms of patient with achalasia: characteristic birdbeak sign is formed by stricture of LES $(A)$ sigmoid shape of oesophagus represents end stage of achalasia (B)
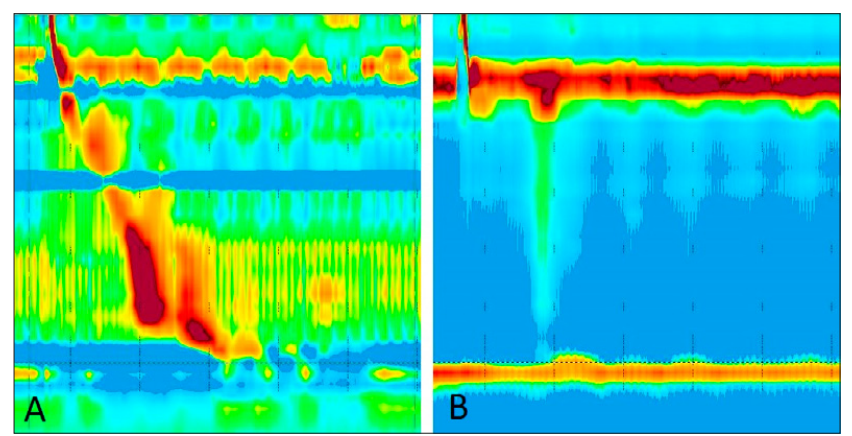

Figure 3. Manometric pattern of intact oesophagal peristalsis with normal LES relaxation (A), compared with manometric presentation of achalasia. Lack of peristalsis accompanied by impaired LES relaxation are typical signs of achalasia (B) 
Manometry. Over the years, conventional water-perfused or strain gauge systems with a line tracing output have evolved to a high-resolution manometry system. Typical findings of conventional manometry were: lack of peristalsis, increased LES pressure with improper relaxation and sometimes elevated intraoesophageal pressure. High-resolution manometry (HRM) was first introduced in 1990 by Clouse and Hebbard; thereafter, it became the gold standard for assessing oesophageal motility and diagnosis of motility disorders [37]. At present, by means of flexible catheter incorporating 36 or more pressure sensors with only $1 \mathrm{~cm}$ intervals, HRM allows detailed pressure recording from the pharynx to the stomach as well as to processes the HRM pressure output to generate oesophageal pressure topography plots (EPT) that represent oesophageal motility and LES function on colour-coded, pressure-space-time plots [44].

After an introduction of the catheter into stomach, patient undergoes a series of 10 liquid swallows in supine position. The standard measurements utilized for analysis include the integrated relaxation pressure (IRP), distal contractile integral (DCI), pressure inversion point (PIP), distal latency $(\mathrm{DL})$, and the contractile front velocity (CFV). The criteria for abnormalities of peristalsis are characterized by contraction vigour, contraction pattern and intrabolus pressure pattern [45]. The Chicago Classification (CC) was introduced in 2009 in order to classify oesophageal motility disorders based upon high-resolution manometry results. Since then it has gained worldwide acceptance resulting in periodic updates in 2012 and 2015 [45]. Integrated relaxation pressure plays a leading role during oesophageal motility evaluation as its elevated value is distinctive for all subtypes of achalasia. It calculates the mean post-swallow LES pressure of a four-second period during which the LES pressure was lowest. According to the Chicago Classification, further differentiation to subclasses I-III depends on the contractility pattern of oesophagus: type I is characterized by $100 \%$ failed peristalsis and no oesophageal pressurization; in type II, panoesophageal pressurization occurs with at least $20 \%$ of swallows, and type III is defined by the presence of preserved fragments of distal peristalsis or premature contractions for at least $20 \%$ of swallows [45].

EGJ outflow obstruction occurs when elevated IRP is not accompanied by disorders of peristalsis underlined in the criteria for achalasia. This may express mechanical obstruction, such as hiatal hernia, extra-oesophageal obstruction, infiltrating disease of the oesophageal wall, or early achalasia [46]. The distinction between subtypes of achalasia also implicates potential effects of treatment. Clinical trials showed that type II is considered to have a good prognosis, moderate results are noted in type I, whereas type III is a predictor of poor response to therapy. HRM with its highest sensitivity of recognizing motility disturbances, should be introduced to patients with non-obstructive dysphagia and/or oesophageal chest pain. Future perspectives of oesophageal motility assessment include high-resolution impedance manometry (HRIM) and impedance planimetry. HRIM provides a direct evaluation of bolus transport that confirms the functional effects of the complex pressure data which is observed during normal eating and drinking behaviour. Impedance planimetry is an imaging technique that is able to display the distensibility and sensitivity of EGJ measuring the cross-sectional area in response to distention. Initial clinical research revealed potential benefits of this method in identifying and quantifying outlet obstruction at the EGJ due to achalasia or former anti-reflux surgery [47].

Treatment. Although several mechanisms referring to possible pathogenesis have been discussed, available treatment modalities are only palliative and achalasia remains incurable. Current therapeutic options include pharmacologic, endoscopic and surgical means, all of which focus on reducing distal oesophageal obstruction, improving oesophageal emptying and relieving patients' symptoms. The decision about treatment should be based on clinical presentation, patient's general condition, experience of the cenre, and the patient's preferences. Prompt diagnosis remains essential for proper management and prevention of progression of the disease.

The presented data are based on the current guidelines of the American College of Gastroenterology (ACG), Society of American Gastrointestinal and Endoscopic Surgeons (SAGES) and the Kagoshima consensus of oesophageal achalasia.

Pharmacologic treatment. The use of orally taken drugs has a minor importance in management of achalasia because of its insufficient efficacy. Medications utilized in treatment are aimed at lowering the LES pressure by smooth muscle relaxation in different mechanisms of action. Nitrates are converted to nitric oxide (NO) which activates the guanylate cyclase, leading to dephosphorylation of the myosin light chain of the muscle fibre; calcium antagonists block calcium entry into the cell, reducing the force of contractions; phosphodiesterase-5-inhibitor blocks an enzyme that promotes breakdown of cyclic guanosine monophosphate cGMP induced by nitric oxide. Other less frequently used agents are anticholinergics, $\beta$-adrenic agonists and theophylline. Nifendypine, a representant of calcium channel blockers, given $30-45$ min before meals in sublinguinal doses of $10-30 \mathrm{mg}$ showed reduction in the LES pressure of $47 \%-64 \%$ [13]. Sublinguinal administration of isosorbide dinitrate may also decrease the LES pressure with a comparable to nifendipine result, but the time needed to achieve maximum action is shorter, hence it should be taken 10-15 min before meals. Additionally, duration of effect in the case of isosorbide dinitrate is also shorter (30-90 min vs 30-120 min in nifedipine). The major drawback of pharmacological therapy is the short acting clinical response, poor improvement of dysphagia, and the side-effects, such as peripheral oedema, headaches or hypotension. According to recent recommendations, pharmacologic therapy should be reserved for patients who cannot or refuse to undergo definitive therapies with either pneumatic dilation or myotomy, and those whose botulin toxin injections failed [6].

Botulinum toxin injection. Botulinum toxin, derived from Clostridium botullinum, is a neurotoxic protein that inhibits exocytosis of acetylocholine into the synaptic area, leading to unopposed cholinergic stimulation and causing a short-term paralysis of the muscle. The intra-sphincteric injection of 80-100 units of botulinum toxin just above the $\mathrm{Z}$ line during an upper gastrointestinal endoscopy, proved to be a userfriendly, easy to perform, safe method with initial clinical response of $90 \%$. Unfortunately, the short-term symptomatic improvement fades rapidly to a $32 \%-60 \%$ response at one year and to $3 \%$ response after two years $[7,43]$. Approximately $50 \%$ 
of patients had syndrome relapse and repeat treatments were required at 6-24 months after the first treatment [6,7]. Doses higher than 100 units didnot produce better results, and the efficacy decreases with each successive injection. Multiple injections may cause inflammatory reaction and fibrosis at the site of injection, which is associated with increased risk of complications in subsequent myotomy. Thus, the botox injection should be particularly limited to elderly patients with comorbidities and contraindications for more definitive therapies [6].

Pneumatic dilation. Pneumatic dilation (PD) shows the most efficient results among the non-surgical treatment modalities of achalasia.[28]. PD is performed with balloons with three different disposable diameters $(3.0,3.5$ and $4.0 \mathrm{~cm})$ that are filled with air and positioned across the LES using fluoroscopy, or with a guidewire placed endoscopically. The procedure is usually performed under sedation with a graded approach, one dilation per session, starting with the smallest balloon. The subsequent dilatations may be repeated at intervals of 2-4 weeks, depending on clinical relief (Eckardt symptom score). It was generally believed that the clinical effectiveness of balloon dilation in achalasia is the result of muscular tearing $[6,28,43]$, although in a recent study, patients were evaluated using endoscopic ultrasound (EUS) $24 \mathrm{~h}$ after PD and muscle interruption was found only in $11.6 \%$ of patients; therefore, balloon dilation is more likely to result in circumferential stretching of muscle fibres [48]. PD appears to be an effective treatment with a remission rate of $93 \%$ in four years follow-up [49]. A similar result was obtained in a meta-analysis of 24 studies of 1,144 individuals, with a mean follow-up of almost three years: good to excellent symptom relief was achieved in $74 \%, 86 \%$ and $90 \%$ of patients, using 30,35 and $40 \mathrm{~mm}$ balloons, respectively [50]. Permanent treatment success in a more than 15 years follow-up was achieved in $40-60 \%$ of patients [38]; however, some patients will develop syndrome recurrence demanding repeated PD. The major and most feared complication of pneumatic dilation is oesophageal perforation, which occurred in $1.9 \%$ of patients after single PD and in $2.6 \%$ after graded PD, which is comparable to the risk of unrecognized perforation during Heller myotomy [51,52]. Gastrographin radiograph is an optional method for the exclusion of oesophageal perforation after procedure, albeit in the case of a high probability of perforation, gastrografin may deteriorate clinical status by mediastinal contamination. In such instances computed tomography identifying free air represents a better choice. Small perforations can be treated conservatively by stent placement, antibiotics and parenteral nutrition; however, large ones require surgical treatment by thoracotomy [6]. Other less severe complications are chest pain, insignificant bleeding, oesophageal haematoma and mucosal tear without perforation. Several predictors of positive outcome has been reported, including age of $>40$ years, female gender, type II achalasia, and LES pressure after dilation $<10 \mathrm{mmHg}$ [7].

Laparoscopic Heller myotomy (LHM). The main and most widely performed surgical procedure for the treatment of patients with achalasia is oesophageal myotomy, first performed in 1913 by Heller [53]. This technique was initially carried out as an open surgery, but over the years was supplanted by a minimally invasive approach, mainly laparoscopically but also robotically. A laparoscopic myotomy proved to be superior to thoracoscopic approach due to reduced postoperative pain, lower rate of morbidity and quicker recovery [54]. The LHM surgery is aimed to alleviate LES obstruction by a longitudinal incision initiated on the anterior side of oesophagus, approximately $4-6 \mathrm{~cm}$ above oesophagogastric junction and extended distally $1.5-$ $3 \mathrm{~cm}$ onto the stomach, to ensure complete relaxation of the cardia. Both muscular layers, longitudinal and circular, are disrupted, as well as serosa. Despite LHM being able to achieve high rates of clinical success, post-operative followup revealed a significant disadvantage of this method development of GERD which was detected in $28-31 \%$ of patients depending on surgical approach (highest rate after laparoscopy) [55]. With that knowledge, Heller myotomy is typically supplemented with an anti-reflux procedure, e.g. an anterior $180^{\circ}$ fundoplasty (Dor) or $270^{\circ}$ partial fundoplication (Toupet). A full $360^{\circ}$ Nissen fundoplication in a randomized controlled trial achieved a result comparable with the Dor technique long-term gastro-oesophageal reflux control; however, the recurrence rate of dysphagia after Nissen procedure was significantly higher [56]. The addition of gastric fundus plication allowed reduction of the gastro-oesophageal reflux rate up to $10 \%[57,58]$, thus making fundoplication a standard supplement of myotomy. In one randomized, controlled trial by Csendes at al., a clinical response at 5 -year follow-up was achieved by $95 \%$ of patients; however, the success rate was reduced to $75 \%$ after a mean follow-up of 15.8 years [59]. Poor outcomes in a great majority of cases were the result of severe reflux disease rather than incomplete myotomy [60]. Heller myotomy is not effective in every case, and some patients may require re-intervention [61]. It has been suggested that the positive effect of therapy is related to an adequate length of myotomy, post-operative LES pressure decrease, and the absence of excessive oesophageal dilation or distortion of the distal oesophagus pre-operatively [58]. Previous endoscopic treatment may be associated with higher morbidity and increased risk of intraoperative complication, but the literature is inconclusive. A cautious approach by a qualified team is recommended [60].

Per-oral Endoscopic Myotomy (POEM). POEM is the latest therapeutic option for patients with achalasia, which was first introduced in 2008 by Inoue in Japan, and since then has spread worldwide [62]. Combining the features of endoscopic dilations (no incision, decreased pain) and LHM (durable surgical myotomy), POEM represents a minimally invasive technique known as a natural orifice transluminal endoscopic surgery (NOTES). The procedure is performed under general anaesthesia and starts with small incision in mid-oesophagus, followed by the creation of submucosal tunnel all the way to oesophagogastric junction using a forward viewing endoscope with triangle tipped knife. This tunnel allows the performance of selective myotomy of the circular muscle for a minimum length of $6 \mathrm{~cm}$ up the oesophagus, and $2 \mathrm{~cm}$ distal to the squamocolumnar junction into the gastric cardia. Opposite to LHM, where the external approach forces sectioning of both muscular layers, in the case of POEM, sectioning of the muscle fibres is focused only on the intrinsic circular layer. Attempts at full-thickness myotomy have reported a shortening in the time of the procedure and higher rate of gastro-oesophageal reflux, compared to circular myotomy [53]. Short-term results achieved a great symptomatic reduction and clinical success rates at 1, 2 and 3 years of $94 \%, 91 \%$ and $90 \%$, respectively. After 
one year follow-up, significant improvement in oesophageal emptying was documented in $93.8 \%$ of patients, while mean LES pressure decreased from $45 \pm 16.5 \mathrm{mmHg}$ pre-operatively to $15.6 \pm 6.1 \mathrm{mmHg}$ post-operatively [63]. A meta-analysis by Marano et al. included 486 patients and showed that POEM had slightly better maintenance of a lower Eckardt score than LHM, but the difference did not reach statistical significance [64]. Moreover, this study revealed no significant difference in post-operative pain score and operative time of LHM and POEM; however, hospital stay after POEM was shorter than after LHM.

The financial aspects of laparoscopic and endoscopic myotomy were also analysed and revealed that POEM incurred significantly less total charges compared to LHM [65]. The rate of complications related to POEM was similar to that encountered in LHM, and included mucosal perforations, bleeding, infections and complications concerning insufflation. Mucosal perforation may be serious problem particularly if it is not recognized quickly. At an early stage the management is simple and should include the use of haemostatic clips or metal stents placement, whereas complicated cases may require surgical intervention. Adverse events related to insufflation, such as pneumoperitoneum or pneumothorax, are most common and occur in about $20 \%$ of cases [66]. They are not usually life-threatening, and pneumoperitoneum can be resolved by transabdominal drainage with a Veres needle.

The main concern about POEM is the development of gastro-oesophageal reflux. Evaluation of GER with gold standard $\mathrm{pH}$ monitoring revealed the presence of pathological reflux in $11.1 \%$ of patients who underwent LHM, and in $47.5 \%$ of patient treated with POEM [67]. Although during POEM only the circular muscular layer is sectioned, and unlike LHM, the procedure does not interfere with other parts of anti-reflux barrier, the lack of additional anti-reflux procedure in POEM might be the main reason for the progression of GER [53]. Further evaluation of the long-term effectiveness is essential for POEM to be consider as a gold standard for the treatment of achalasia.

Follow-up and future perspectives. The emergence of high-resolution manometry has led to the categorisation of achalasia into 3 subtypes which allow the prediction of possible outcome after therapy. There are evidences of best prognosis in type II, opposite to patients with type III who are expected to have a worse response. Overall treatment effectiveness may be improved by choosing the proper therapy for each different patient classified according to subclassification. Existing treatment is only palliative and none of available treatment modalities is able to achieve complete success; therefore, up to $56 \%$ of patients may require additional treatment within 5 years [68]. Temporal placement of wide, partially covered self-expandable metal stents (SEMS) appears to be an alternative treatment specially in high-risk surgical patients. Stenting is also considered as a therapy of choice for those cases after primary treatment failure, offering an efficacious, well-tolerated option [69]. Patients with achalasia should have periodic postoperative follow-up in order to estimate the efficacy of treatment, as well as to determine whether further interventions are required. The optimal approach in providing follow-up includes evaluation of syndrome relief, nutrition status, oesophageal emptying by timed barium swallow, and HRM. Due to oesophageal stasis, bacterial overgrowth followed by inflammation and dysplasia, patients with achalasia have increased risk of squamous carcinoma of oesophagus [38]. Present guidelines do not recommend surveillance endoscopy for oesophageal cancer; however, a plan for follow-up should be generated individually, and in cases with primarily higher risk of cancer or among those who develop post-operative GER, endoscopic assessment seems reasonable [13].

In the future, further prospective studies are needed to establish optimal, tailored-to- patient treatment. Promising findings were revealed in recent study presenting the benefits of the intraoperative HRM in modification of myotomy [68]. Finally, the growing insight into the pathophysiology of achalasia, particularly the immunological aspects, may result in innovative treatment aimed at halting the disease at an early stage [29].

\section{REFERENCES}

1. Patel DA, Kim HP, Zifodya JS, Vaezi MF. Idiopathic (primary) achalasia: a review. Orphanet J Rare Dis.

2. Wangensteen $\mathrm{OH}$. A physiologic operation for mega-oesophagus: (dystonia, cardiospasm, achalasia). Ann Surg. 1951; 134(3): 301-318.

3. Birgisson S, Richter JE. Achalasia: what's new in diagnosis and treatment? Dig Dis. 1997; 15 Suppl 1: 1-27.

4. Creamer B, Ellis FH, Olsen AM. Cardiospasm (achalasia of the cardia). Am J Surg. 1957; 93(2): 299-307.

5. Sadowski DC, Ackah F, Jiang B, Svenson LW. Achalasia: incidence, prevalence and survival. A population-based study. Neurogastroenterol Motil. 2010; 22(9): e256-e261.

6. Vaezi MF, Pandolfino JE, Vela MF. ACG clinical guideline: diagnosis and management of achalasia. Am J Gastroenterol. 2013; 108(8): 1238-49.

7. Torresan F, Ioannou A, Azzaroli F, Bazzoli F. Treatment of achalasia in the era of high-resolution manometry. Annals of gastroenterology. 2015; 28(3): 301-308.

8. Samo S, Carlson DA, Gregory DL, Gawel SH, Pandolfino JE, Kahrilas PJ. Incidence and Prevalence of Achalasia in Central Chicago, 20042014, Since the Widespread Use of High-Resolution Manometry. Clin Gastroenterol Hepatol. 2017; 15(3): 366-373.

9. Chedid V, Rosenblatt E, Gandhi KK, Dhalla S, Nandwani MC, Stein EM, et al. The Effect of Race in Patients with Achalasia Diagnosed With High-Resolution Oesophageal Manometry. Am J Med Sci. 2018; 355(2): 126-131.

10. Francis DL, Katzka DA. Achalasia: update on the disease and its treatment. Gastroenterology. 2010; 139(2): 369-374.

11. Goyal RK, Chaudhury A. Physiology of normal oesophageal motility. J Clin Gastroenterol. 2008; 42(5): 610-619.

12. Park W, Vaezi MF. Etiology and pathogenesis of achalasia: the current understanding. Am J Gastroenterol. 2005; 100(6): 1404-1414.

13. Pandolfino JE, Gawron AJ. Achalasia: a systematic review. JAMA. 2015; 313(18): 1841-1852.

14. Villanacci V, Annese V, Cuttitta A, Fisogni S, Scaramuzzi G, De Santo E, et al. An immunohistochemical study of the myenteric plexus in idiopathic achalasia. J Clin Gastroenterol. 2010; 44(6): 407-410.

15. Kahrilas PJ, Boeckxstaens G. The spectrum of achalasia: lessons from studies of pathophysiology and high-resolution manometry. Gastroenterology. 2013; 145(5): 954-65.

16. Bosher LP, Shaw A. Achalasia in siblings. Clinical and genetic aspects. Am J Dis Child. 1981; 135(8): 709-710.

17. Stein DT, Knauer CM. Achalasia in monozygotic twins. Dig Dis Sci. 1982; 27(7): 636-640.

18. Shteyer E, Edvardson S, Wynia-Smith SL, Pierri CL, Zangen T, Hashavya $S$, et al. Truncating mutation in the nitric oxide synthase 1 gene is associated with infantile achalasia. Gastroenterology. 2015; 148(3): 533-536.e4.

19. Paladini F, Cocco E, Cascino I, Belfiore F, Badiali D, Piretta L, et al. Agedependent association of idiopathic achalasia with vasoactive intestinal peptide receptor 1 gene. Neurogastroenterol Motil. 2009; 21(6): 597-602.

20. de León AR, de la Serna JP, Santiago JL, Sevilla C, Fernández-Arquero $\mathrm{M}$, de la Concha EG, et al. Association between idiopathic achalasia and IL23R gene. Neurogastroenterol Motil. 2010; 22(7): 734-8, e218. 
21. Nuñez C, García-González MA, Santiago JL, Benito MS, Mearín F, de la Concha EG, et al. Association of IL10 promoter polymorphisms with idiopathic achalasia. Hum Immunol. 2011; 72(9): 749-752.

22. Evsyutina YV, Trukhmanov AS, Ivashkin VT. Family case of achalasia cardia: case report and review of literature. World journal of gastroenterology. 2014; 20(4): 1114-1118.

23. Latiano A, Palmieri O, Bossa F, Latiano T, Corritore G, De Santo E, et al. Impact of genetic polymorphisms on the pathogenesis of idiopathic achalasia: Association with IL33 gene variant. Hum Immunol. 2014; 75(4): 364-369.

24. Santiago JL, Martínez A, Benito MS, Ruiz de León A, Mendoza JL, Fernández-Arquero M, et al. Gender-specific association of the PTPN22 C1858T polymorphism with achalasia. Hum Immunol. 2007; 68(10): $867-870$.

25. Kurnaz E, Duminuco P, Aycan Z, Savaş-Erdeve Ş, Muratoğlu Şahin $\mathrm{N}$, Keskin $\mathrm{M}$, et al. Clinical and genetic characterisation of a series of patients with triple A syndrome. Eur J Pediatr. 2018; 177(3): 363-369.

26. Ghoshal UC, Daschakraborty SB, Singh R. Pathogenesis of achalasia cardia. World journal of gastroenterology. 2012; 18(24): 3050-3057.

27. Niwamoto H, Okamoto E, Fujimoto J, Takeuchi M, Furuyama J, Yamamoto Y. Are human herpes viruses or measles virus associated with oesophageal achalasia? Dig Dis Sci. 1995; 40(4): 859-864.

28. Vaezi MF, Richter JE. Diagnosis and management of achalasia. American College of Gastroenterology Practice Parameter Committee. Am J Gastroenterol. 1999; 94(12): 3406-3412.

29. Furuzawa-Carballeda J, Torres-Landa S, Valdovinos MÁ, Coss-Adame E, Martín Del Campo LA, Torres-Villalobos G. New insights into the pathophysiology of achalasia and implications for future treatment. World J Gastroenterol. 2016; 22(35): 7892-907.

30. Abubakar U, Bashir MB, Kesieme EB. Pseudoachalasia: A review. Niger J Clin Pract. 2016; 19(3): 303-307.

31. Ravi K, Sweetser S, Katzka DA. Pseudoachalasia secondary to bariatric surgery. Dis Oesophagus. 2016; 29(8): 992-995.

32. Gockel I, Eckardt VF, Schmitt T, Junginger T. Pseudoachalasia: a case series and analysis of the literature. Scand J Gastroenterol. 2005; 40(4): $378-385$

33. Sinan H, Tatum RP, Soares RV, Martin AV, Pellegrini CA, Oelschlager BK. Prevalence of respiratory symptoms in patients with achalasia. Dis Oesophagus. 2011; 24(4): 224-228.

34. Gupta M, Ghoshal UC, Jindal S, Misra A, Nath A, Saraswat VA. Respiratory dysfunction is common in patients with achalasia and improves after pneumatic dilation. Dig Dis Sci. 2014; 59(4): 744-752.

35. Eckardt VF, Köhne U, Junginger T, Westermeier T. Risk factors for diagnostic delay in achalasia. Dig Dis Sci. 1997; 42(3): 580-585.

36. Eckardt VF, Aignherr C, Bernhard G. Predictors of outcome in patients with achalasia treated by pneumatic dilation. Gastroenterology. 1992; 103: 1732-1738.

37. Dimitriu A, Gheorghe C. High Resolution Manometry - A Mandatory Examination in the Pre- and Postoperative Assessment of Patients with Achalasia. Chirurgia (Bucur). 2018; 113(1): 61-69.

38. Eckardt AJ, Eckardt VF. Current clinical approach to achalasia. World Journal of Gastroenterology. 2009; 15(32): 3969-3969.

39. Ates F, Vaezi MF. The Pathogenesis and Management of Achalasia: Current Status and Future Directions. Gut Liver. 2015; 9(4): 449-63.

40. de Borst JM, Wagtmans MJ, Fockens P, van Lanschot JJ, West R, Boeckxstaens GE. Pseudoachalasia caused by pancreatic carcinoma. Eur J Gastroenterol Hepatol. 2003; 15(7): 825-828.

41. Howard PJ, Maher L, Pryde A, Cameron EW, Heading RC. Five year prospective study of the incidence, clinical features, and diagnosis of achalasia in Edinburgh. Gut. 1992; 33(8): 1011-1015.

42. Minami H, Isomoto H, Miuma S, Kobayashi Y, Yamaguchi N, Urabe S, et al. New endoscopic indicator of oesophageal achalasia: "pinstripe pattern”. PLoS One. 2015; 10(2): e0101833. doi:10.1371/journal. pone. 0101833

43. Triadafilopoulos G, Boeckxstaens GE, Gullo R, Patti MG, Pandolfino JE, Kahrilas PJ, et al. The Kagoshima consensus on oesophageal achalasia. Dis Oesophagus. 2012; 25(4): 337-348.

44. Carlson DA, Pandolfino JE. High-Resolution Manometry in Clinical Practice. Gastroenterol \& Hepatol (N Y). 2015; 11(6): 374-384.

45. Kahrilas PJ, Bredenoord AJ, Fox M, Gyawali CP, Roman S, Smout AJPM, et al. International High Resolution Manometry Working Group: The Chicago Classification of oesophageal motility disorders, v3.0. Neurogastroenterol Motil. 2015; 27(2): 160-174.

46. Scherer JR, Kwiatek MA, Soper NJ, Pandolfino JE, Kahrilas PJ. Functional esophagogastric junction obstruction with intact peristalsis: a heterogeneous syndrome sometimes akin to achalasia. J Gastrointest Surg. 2009; 13(12): 2219-2225.
47. Fox M, Sweis R. Future directions in oesophageal motility and function - new technology and methodology. Neurogastroenterol Motil. 2012; 24: 48-56. doi:10.1111/j.1365-2982.2011.01835.x.

48. Borhan-Manesh F, Kaviani MJ, Taghavi AR. The efficacy of balloon dilation in achalasia is the result of stretching of the lower oesophageal sphincter, not muscular disruption. Dis oesophagus. 2016; 29(3): 262266.

49. Shah SWH, Butt AK, Malik K, Alam A, Khan AA. Pneumatic Balloon Dilatation for Achalasia Cardia; Early \& late results, a single center study. Pak J Med Sci. 2017; 33(5): 1053-1058.

50. Richter JE. Update on the management of achalasia: balloons, surgery and drugs. Expert Rev Gastroenterol Hepatol. 2008; 2(3): 435-445.

51. Vela MF, Richter JE, Khandwala F, Blackstone EH, Wachsberger D, Baker ME, et al. The long-term efficacy of pneumatic dilatation and Heller myotomy for the treatment of achalasia. Clin Gastroenterol Hepatol. 2006; 4(5): 580-587.

52. Lynch KL, Pandolfino JE, Howden CW, Kahrilas PJ. Major complications of pneumatic dilation and Heller myotomy for achalasia: single-center experience and systematic review of the literature. Am J Gastroenterol. 2012; 107(12): 1817-1825.

53. Tefas C, Ababneh R, Tanțău M. Peroral Endoscopic Myotomy Versus Heller Myotomy for Achalasia: Pros and Cons. Chirurgia (Bucur). 2018; 113(2): 185-191.

54. Ali A, Pellegrini CA. Laparoscopic myotomy: technique and efficacy in treating achalasia. Gastrointest Endosc Clin N Am. 2001; 11(2): 347-58.

55. Campos GM, Vittinghoff E, Rabl C, Takata M, Gadenstätter M, Lin F, et al. Endoscopic and surgical treatments for achalasia: a systematic review and meta-analysis. Ann Surg. 2009; 249(1): 45-57.

56. Rebecchi F, Giaccone C, Farinella E, Campaci R, Morino M. Randomized controlled trial of laparoscopic Heller myotomy plus Dor fundoplication versus Nissen fundoplication for achalasia: long-term results. Ann Surg. 2008; 248(6): 1023-1030.

57. Anselmino M, Zaninotto G, Costantini M, Rossi M, Boccu C, Molena $D$, et al. One-year follow-up after laparoscopic Heller-Dor operation for oesophageal achalasia. Surg Endosc. 1997; 11(1): 3-7.

58. El Hak NG, Hamdy E, Abdalla T, Kandel T, El Raof AA, El Hemaly M, et al. Laparoscopic Heller myotomy for achalasia: analysis of successes and failures. Hepatogastroenterology. 2012; 59(117): 1450-1454.

59. Csendes A, Braghetto I, Burdiles P, Korn O, Csendes P, Henríquez A. Very late results of oesophagomyotomy for patients with achalasia: clinical, endoscopic, histologic, manometric, and acid reflux studies in 67 patients for a mean follow-up of 190 months. Ann Surg. 2006; 243(2): 196-203.

60. Stefanidis D, Richardson W, Farrell TM, Kohn GP, Augenstein V, Fanelli RD. Society of American Gastrointestinal and Endoscopic Surgeons: SAGES guidelines for the surgical treatment of oesophageal achalasia. Surg Endosc. 2012; 26(2): 296-311.

61. Francis DL, Katzka DA. Achalasia: Update on the Disease and Its Treatment. Gastroenterology. 2010; 139(2): 369-374.

62. Inoue H, Minami H, Kobayashi Y, Sato Y, Kaga M, Suzuki M, et al. Peroral endoscopic myotomy (POEM) for oesophageal achalasia. Endoscopy. 2010; 42(4): 265-271.

63. Nabi Z, Ramchandani M, Chavan R, Kalapala R, Darisetty S, Rao G, et al. Per-oral endoscopic myotomy for achalasia cardia: outcomes in over 400 consecutive patients. Endosc Int Open. 2017; 05(05): E331-E339.

64. Marano L, Pallabazzer G, Solito B, Santi S, Pigazzi A, De Luca R, et al. Surgery or Peroral Oesophageal Myotomy for Achalasia: A Systematic Review and Meta-Analysis. Medicine (Baltimore). 2016; 95(10): e3001.

65. Khashab MA, Kumbhari V, Tieu AH, El Zein MH, Ismail A, Ngamruengphong S, et al. Peroral endoscopic myotomy achieves similar clinical response but incurs lesser charges compared to robotic heller myotomy. Saudi J Gastroenterol. 2017; 23(2): 91-96.

66. Talukdar R, Inoue H, Nageshwar Reddy D. Efficacy of peroral endoscopic myotomy (POEM) in the treatment of achalasia: a systematic review and meta-analysis. Surg Endosc. 2015; 29(11): 3030-3046.

67. Schlottmann F, Luckett DJ, Fine J, Shaheen NJ, Patti MG. Laparoscopic Heller Myotomy Versus Peroral Endoscopic Myotomy (POEM) for Achalasia: A Systematic Review and Meta-analysis. Ann Surg. 2018; 267(3): 451-460

68. Triantafyllou T, Theodoropoulos C, Georgiou G. Long-term outcome of myotomy and fundoplication based on intraoperative real-time high-resolution manometry in achalasia patients. Ann Gastroenterol. 2018; 32(1): 46-51.

69. Sioulas AD, Malli C, Dimitriadis GD, Triantafyllou K. Self-expandable metal stents for achalasia: Thinking out of the box!. World J Gastrointest Endosc. 2015; 7(1): 45-52. 